\title{
RESEARCH ON INCREASING THE DEGREE OF INDIVIDUAL PROTECTION AGAINST BULLETS THROUGH THE USE OF CERAMIC MATERIALS
}

\author{
Florin ILIE \\ ilieflorinv@yahoo.com
}

“NICOLAE BALCESCU” LAND FORCES ACADEMY, SIBIU, ROMANIA

\begin{abstract}
The protection of forces in the new world conflicts has become a particularly important issue for all the world's armies. Therefore, ensuring an optimal level of protection, combined with maintaining freedom of movement in the tactical field has become a very important topic for research teams. This goal can be achieved by using materials in the protection of forces with a relatively low mass, but to ensure a substantial reduction in the kinetic energy of ballistic penetrators. In this paper are presented some considerations on how the ballistic penetration process is affected by the presence of ceramic materials.
\end{abstract}

\section{KEYWORDS:}

Ceramic materials, individual protection, bullets, impact

\section{Conceptual delimitations}

Any element of the individual protective equipment imposes a barrier between the wearer and the work environment. This can create additional pressure on the wearer, affect his ability to perform the task and create various significant levels of discomfort. Any of these can discourage people wearing individual protective equipment from using it properly and therefore increase the risk of injury, illness or even extreme cases, such as the death of people exposed at risks. Therefore, a balance must be struck between mobility and the level of protection of forces.

One of the most important goals of researchers around the world is to bring more safety to the military involved in various military operations and missions in theaters of operations, especially in Afghanistan. In the terms of today's warfare, personal protective equipment, bulletproof vest and helmets have become a must-have equipment in the endowment of the soldiers and are made with the help of state-of-the-art technology, oferring miscellaneous levels of protection and increased mobility of forces.

This paper aims to bring more knowledge in the use of ceramic materials for the protection of forces and, in particular, in testing how they ensure the protection of forces.

\section{Theoretical considerations}

The impact of the ballistic penetrator with the armor system is part of the category of mechanical collisions in which one of the two colliding bodies (armor) is at rest. 
The impulsive force of the projectile is characterized by an almost instantaneous increase (10-6 s) to a maximum value. Immediately after this, the impulsive force decreases to zero.

The duration of the impulsive force is in the order of hundreds of microseconds (Gadzalov \& Krastev, 2009).

If we note with $\Delta V$ the variation of the projectile speed during the collision with the armor and with $\Delta t$ the very short time interval in which the collision takes place,

$$
\frac{\Delta V}{\Delta t}=a_{\text {med }},
$$

can be defined as an average acceleration, corresponding to the movement of the projectile within the time $\Delta t$.

The size $\Delta V$ being a finite size, and $\Delta t$ a very small one, it results that during the collision of the projectile with the armor there is an acceleration $a_{m e d}$ very large, so also an average force $F_{m e d}$, very large (Liu, 2010):

$$
F_{\text {med }}=m_{p} \cdot a_{\text {med }} .
$$

In the mechanics of collisions, impulsive forces, such as those that occur when the projectile collides with the armor, are also known as percussive forces. Therefore, the percussion $\mathrm{P}$ can also be defined as

$$
P=F_{\text {med }} \cdot \Delta t
$$

or

$$
P=m_{p} \cdot \Delta V .
$$

This means that the variation of the projectile's impulse during the collision with the armor is equal to the percussion acting on the armor (Năstăsescu, \& Bârsan, 2015).

In the study of the impulsive forces that appear at the impact of the projectilearmor, the distribution of these forces on the unit of contact surface (pressure) between the projectile and the armor as a function of time is of greater interest.

3. Numerical simulation and actual firing from the firing range to test the impact of the bullet with the proposed protection system

To simulate the impact phenomenon between the bullet and the proposed forces protection system, we used the SPH solver according to the recommendations of the specialized literature (Năstăsescu \& Iliescu, 2009). The solver is a Lagrange technique and, due to its flexibility in calculating the forces from spatial derivatives of tension and in the calculation of deformation velocities starting from the spatial derivatives of the velocity, has the advantage of accurately shaping interfaces, especially in the case of the impact of highspeed ballistic penetrators (Năstăsescu \& Bârsan, 2012).

\subsection{Wording of the problem to solve}

In our research, as well as in the tests with combat ammunition performed in the polygon we used ammunition of $7.62 \mathrm{~mm}$ caliber. The proposed protection structure for the protection of forces was made of a SINTOX ceramic plate, $8 \mathrm{~mm}$ thick, superimposed on a $6 \mathrm{~mm}$ steel control block (Figure no. 1). We also considered an angle of incidence between the bullet and the ballistic protection structure at the time of impact of 900 . The initial velocity of the bullet at the exit of the pipe is $715 \mathrm{~m} / \mathrm{s}$. 


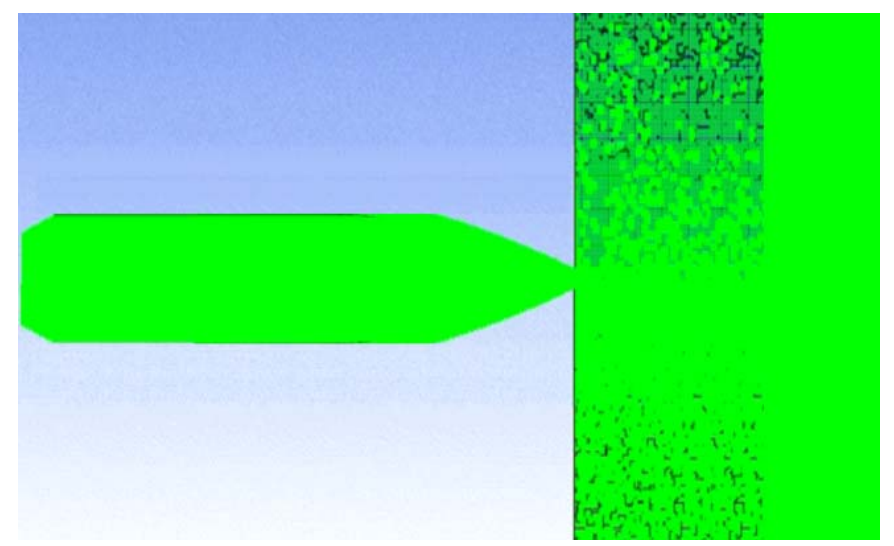

Figure no. 1: Mathematical shaping at the time of impact

(Source: Ilie, 2012)

Following the simulations performed with the help of the analysis program, we obtained data, images and video simulations of the impact phenomenon between the ballistic penetrator and the proposed armor system. These simulations provide data showing how the ceramic plate is drilled and destroyed, as well as information about the deformed state, velocity field, deformation field, bullet kinetic energy, etc. (Figure no. 2).

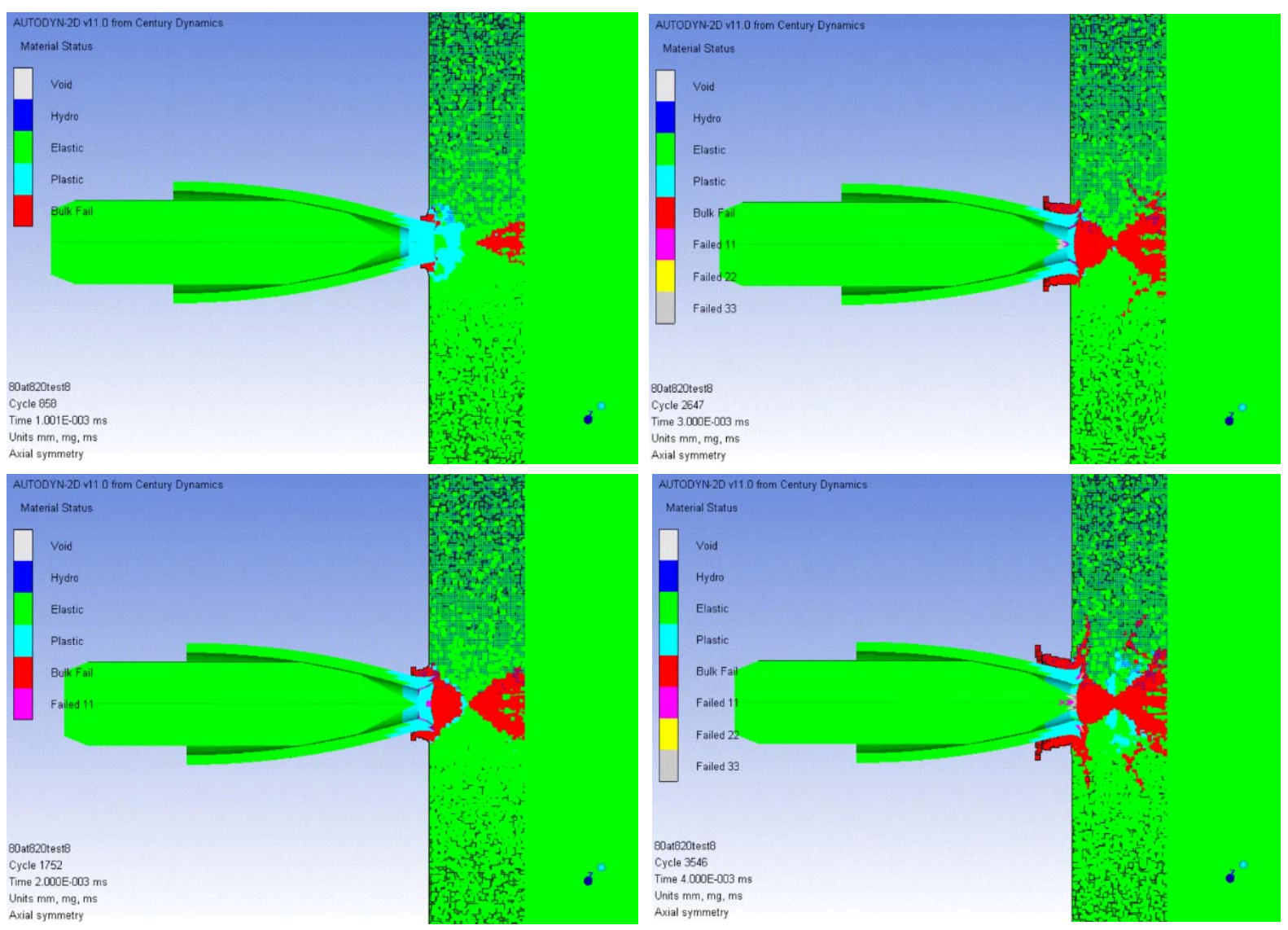

Figure no. 2: Numerical simulation during the perforation

(Source: Author) 
In our research we aimed to verify whether the experimentally obtained data are consistent with the real aspects of the impact phenomenon between a ballistic penetrator and the proposed force protection system, which includes a ceramic plaque (Figure no. 3). The tests were performed from different distances to the target, with and without the ceramic protection system.

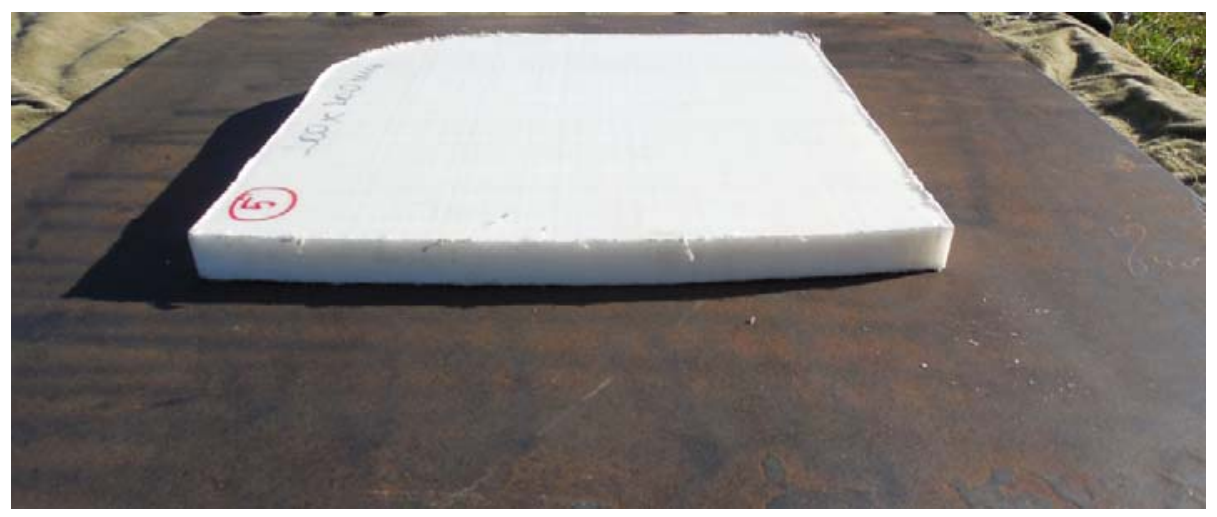

Figure no. 3: The ceramic pre-firing protection system

(Source: Author)

The tests (Figure no. 4) were performed at different distances on the target, with and without the ceramic protection system and aimed at how it reduces the speed of the bullet, as well as stopping the penetration into the control block. It consisted of a metal plate measuring $60 \times 60 \times 2[\mathrm{~cm}]$.

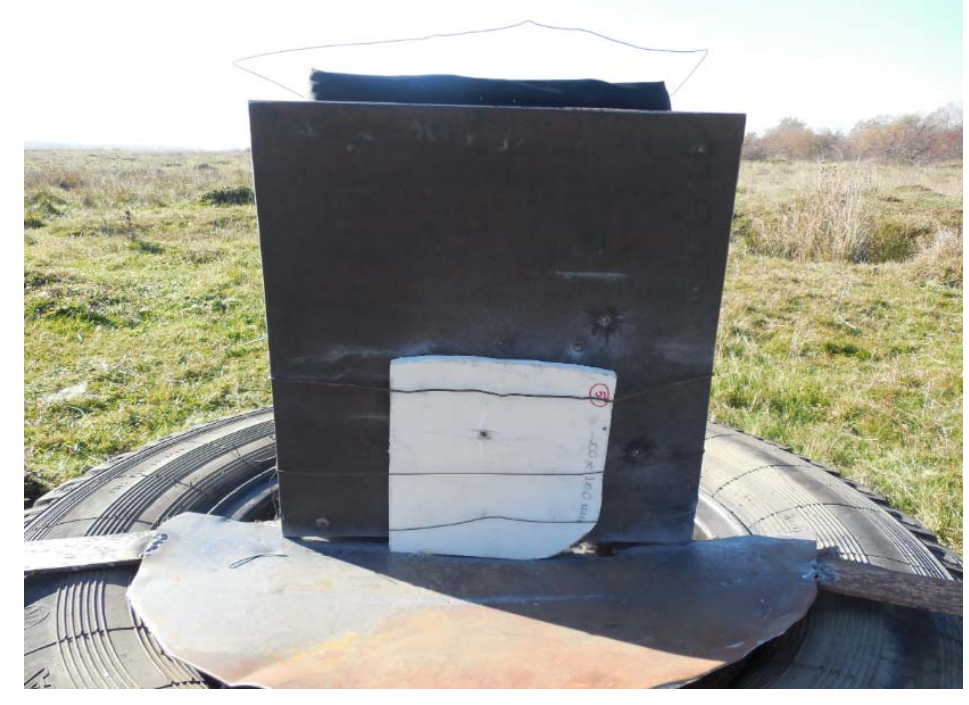

Figure no. 4: The proposed system before firing

(Source: Author)

For the tests we used the 1963 submachine gun and the $7.62 \times 39 \mathrm{~mm}$ ammunition, with a steel core bullet. The maximum pressure achieved in the cartridge chamber reaches the value of $310.3 \mathrm{MPa}(45,010 \mathrm{psi})$ (SAAMI) and ensures the bullet (Figure no. 5) an initial speed of $715 \mathrm{~m} / \mathrm{s}$. 


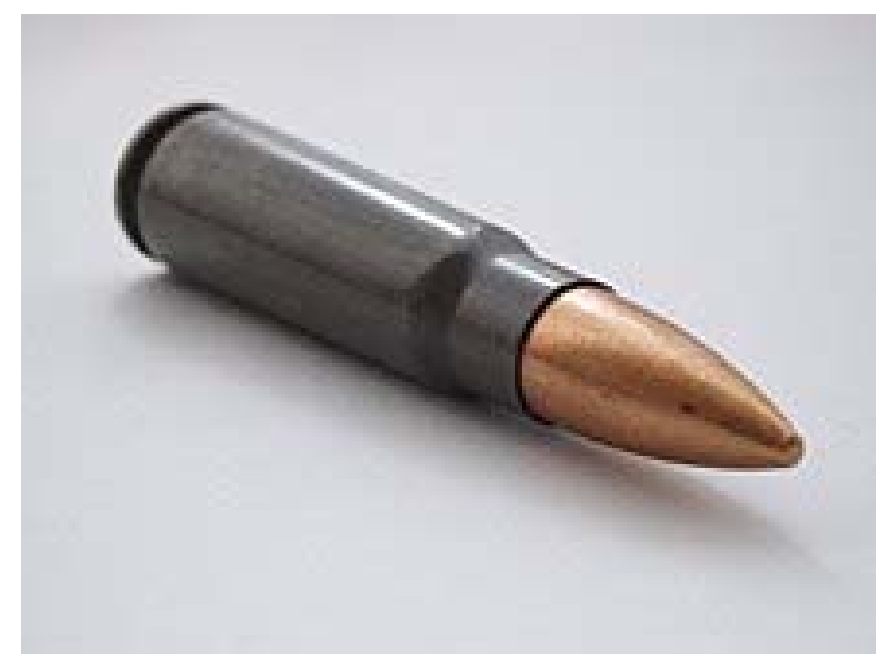

Figure no. 5: The $7.62 \times 39 \mathrm{~mm}$ bullet used in ballistic tests

(Source: Ilie \& Trocan, 2017)

As expected, from the data from the was pierced by the bullet, in the absence of literature (Ilie \& Trocan, 2017), the slab the ceramic slab (Figure no. 6).

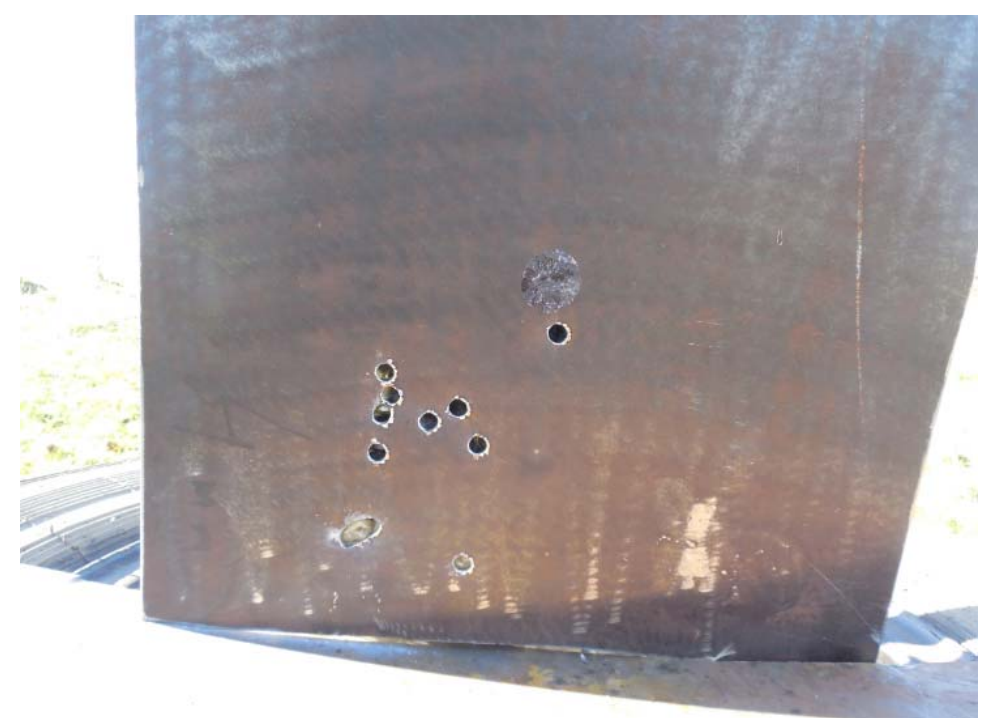

Figure no. 6: The perforation of the metal control block by bullets in the absence of the ceramic structure

(Source: Author)

It should be mentioned that in this figure the system proposed by us also includes a kevlar plaque behind the metal control block, which retained the ballistic penetrator.

Following the theoretical study and mathematical shaping, it was found that in the presence of a ceramic plaque the bullet speed is considerably reduced. This was demonstrated by the actual firing in the firing range, as a result of which the bullet did not have enough kinetic energy even to penetrate the control block. The only visible aspect of the impact between the bullet and the metal control block was a scratch left on the surface of the metal plaque (Figure no. 7). 


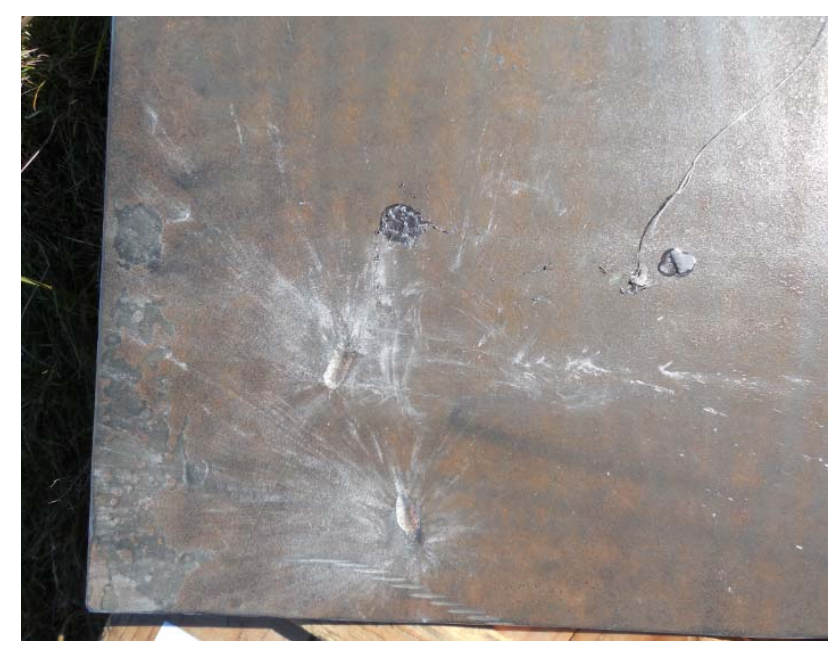

Figure no. 7: Traces left on the surface of the control block after impact (original)

(Source: Author)

Another relevant aspect that resulted from the tests performed in the polygon, with the same materials and the same ballistic penetrator as in the numerical simulations, was the breaking of the ceramic plaque. This is perfectly normal, due to the impact at very high speeds (hundreds of meters per second) generated by the $7.62 \mathrm{~mm}$ bullet.

\section{Conclusions}

The way in which the impact is made between a bullet and an individual protection structure at very high speeds is an extremely complex phenomenon that continues to concern the world's researchers and armies. The essence of characterizing this phenomenon is given by the study of the effect of the bullet when hitting the target. Another very important aspect is the way in which a real protection of forces can be achieved by using high quality materials, which, at the same time, do not bring negative parameters in the logistics and mobility of troops, such as too much increase. of the mass of the protective vests.

That is why, in this paper we approached the study of a material that supports the protection of forces, namely the ceramic structure. The very high value of the kinetic energy when the ballistic penetrator hits the ceramic plaque is absorbed by it, and the result is its breaking due primarily to the intensity of the shock generated by the impact between the bullet and the armor.

Through our study we wanted to bring an extra knowledge in this extremely complex process, which is the impact phenomenon between a ballistic penetrator with very high speeds and a bliding structure that also contains ceramic material.

Comparing the results obtained in the tests performed in the polygon, with real firing with $7.62 \mathrm{~mm}$ ammunition with the results calculated by numerical shaping, we notice that the error between the two types of data does not exceed $10 \%$. This percentage allows us to believe that we are in the range of technical errors and to understand that numerical simulation and mathematical analysis of impact phenomena can become an indispensable calculation tool in modern ammunition design and can also improve protection capabilities of forces in modern armies by using ceramic materials. 


\section{REFERENCES}

Gadzalov, N.D., \& Krastev, K.I. (2009). The use of "force to force" shooting training systems in the "Future officers" training. Vasil Levski NMU Annual Scientific Conference, Veliko Tarnovo: NMU Publisher.

Ilie, F. (2012). Research on Protection Materials Behavior at Their Projectile and Armor Impact. The XVIII International Conference "The Knowledge-Based Organization" Conference Proceedings, Sibiu: "Nicolae Bălcescu” Land Forces Academy Publishing House, 248-251.

Ilie, F., \& Trocan, C. (2017). Arme mici (Small Arms) în armatele moderne. Sibiu: Editura Academiei Forțelor Terestre "Nicolae Bălcescu".

Liu, G.R. (2010). Meshfree Methods, Mooving Beyond the Finite Element Method. $2^{\text {nd }}$ Edition, CRC Press Taylor \& Francis Group, LLC, ISBN 978-1-4200-8209.

Năstăsescu, V., \& Bârsan, Gh. (2012). Metoda SPH (Smoothed Particle Hydrodynamics). Sibiu: Editura Academiei Forțelor Terestre "Nicolae Bălcescu", ISBN 978-973-153-130-4.

Năstăsescu, V., \& Bârsan, Gh. (2015). Metoda particulelor libere în analiza numerică a mediilor continue. Bucharest: Editura AGIR, ISBN 978-973-720-617-6.

Năstăsescu, V., \& Iliescu, N. (2009). Numerical Simulation of the Impact Problems by SPH Method. Proceedings of IV th National Conference the Academic Days of Academy of Technical Science in Romania, Vol. 1, 193-198, Iaşi: AGIR Publishing House, ISSN: 2066-6586. 